\title{
An Analytic Valuation of a Deposit Insurance
}

\author{
Endah RM Putri*, Venansius R Tjahjono and Daryono B Utomo \\ Department of Mathematics, Sepuluh Nopember Institute of Technology \\ Jl. Raya ITS, Sukolilo, Surabaya, 60111, Indonesia \\ ${ }^{*}$ Corresponding author: endahrmp@matematika.its.ac.id
}

Article history

Received: 30 August 2018

Received in revised form: 13 December 2018

Accepted: 20 December 2018

Published on line: 31 December 2018

\begin{abstract}
A deposit insurance is a measure to protect bank's depositors fully or partly from the risk of losses caused by the banks failure to pay its debts when due. If the bank does not meet the payment since the asset value of the bank is less than debt, the guarantor will do the payment and take over the bank's assets. The role of the guarantor is considered as a deposit insurance. Similar mechanism of the insurance to the European put option model, motivates the use of a Black-Scholes model in the valuation. The deposit insurance model is solved using a Fourier transform method analytically. Numerical results based on the solution confirms the results obtained by previous research. Also, some behaviours of the deposit insurance premium due to interest rate, volatility, and deposit-to-asset value ratio are presented.
\end{abstract}

Keywords Deposit insurance; analytic valuation; Fourier transform; Black-Scholes model

Mathematics Subject Classification 46N60, $92 \mathrm{~B} 99$.

\section{Introduction}

The fundamental role of a bank is to lend funds for another party, which can be a company or a specific person. A bank also provides deposit services to individual. Deposit services are one of many policies to safe-keeping our money in bank during specific periods of time [1]. The benefits of deposit services are due to a high rate of interest through specific terms, safe investments, and guaranteed returns. Regarding the benefits of deposit, it can be deduced that deposit services has low probability of actually losing money. This bank crisis puts pressure on government to assure that depositor's asset is safe. Nevertheless, if the bank fails to pay its debt, our deposits can be lost. Therefore, a measure is required to guarantee the bank depositors from risks. This measure is called as a deposit insurance. The ability to produce a good estimate for the economic value of a deposit insurance contract is the key to any workable policy initiative [2].

Deposit insurance systems are regulated by an agency such as Federal Deposit Insurance Corporation (FDIC) in the US. Each depositor is insured by FDIC to at least $\$ 250,000$ per insured bank. FDIC will cover depositor's money at each insured bank, but does not guarantee 
stocks, bonds, mutual funds, life insurance policies or annuities, even though these investments are purchased at an insured bank.

Similar agency in Indonesia is called Lembaga Penjamin Simpanan (LPS) or Indonesia Deposit Insurance Corporation (IDIC). Set back to the financial crisis in 1998 in Indonesia, a blanket guarantee system is proven to restore public confidence in the banking system although an additional fiscal burden is arisen and a potential moral hazard exposed. To avoid these issues, Indonesia has adopted the Deposit Insurance Corporation Law (Act No. 24 of 2004) and the Indonesian Deposit Insurance Corporation (IDIC) is initiated to replace the blanket guarantee scheme. The DIC scheme has a limited coverage to reduce the fiscal burden and maintain an optimum level of customer protection [3]. Furthermore, Bank Indonesia and the government developed a Draft Law of Financial System Safety Net (FSSN) in 2005 which aims to maintain the stability of the financial system for a sustainable economic development. Three relevant institutions : the Ministry of Finance, Bank Indonesia (BI) and the Indonesian Deposit Insurance Corporation (IDIC), are responsible for, respectively, drafting the legislation for financial sector, safeguard the monetary stability, and guarantee bank customer deposits. An explicit scheme is used so that the deposit insurance scheme is being phased in over an extended period and the bank customer deposit guarantee will be restricted to $\mathrm{Rp} 100$ million per account [3].

There are considerable methods can be used to evaluate the value of deposit insurance [4-6]. The valuation of deposit insurance as an option model is discussed by some researchers. Merton [7] provided an isomorphic correspondence between the cost of deposit insurance and a European put option under the Black-Scholes model. Duan and Yu [2] already applied Merton's journal for assessing the cost of Taiwan's deposit insurance. Moreover, Marcus and Shaked [8] developed an alternative Black-Scholes model with dividend for doing empirical studies of deposit insurance premium based on the option pricing method. A similar mechanism between a deposit insurance and a put option contract, motivate us to review the studies about option pricing methods.

In the popular paper by Black and Scholes [9], analytical solutions of pricing a European option has been presented. Since then, similar works in obtaining analytical solutions of European options pricing have been obtained. Carr and Madan [10] proposed the use of a fast Fourier transform in obtaining the analytical solution by assuming that the characteristic function of return is known analytically. As an alternative, a Fourier series expansion is used by Fang and Osterlee [11] for pricing some options including a European option. A faster pricing is obtained by their method. Jiang [12] and Wilmott [13] have also presented the use of Fourier transform to solve the Black-Scholes model based on its partial differential equation. In this paper, we propose the use of Fourier transform to solve the valuation of deposit insurance based on Black-Scholes model.

This paper is organized as follows: introduction and background of deposit insurance valuation in Section 1, deposit insurance structure and modelling in Section 2 and 3, Fourier transform for analytic solution in Section 4, solution process in Section 5, simulation studies in Section 6, and concluding remarks in Section 7. 


\section{A Deposit Insurance Mechanism}

A deposit insurance is an insurance to protect the bank's depositors from the risk of banks failure, to repay their loans when due. Consider that a bank issues a debt for borrowing money and promises to payback on a specified date (maturity date). In case the bank fails to fulfill its obligation to payback, the bank has to default by surrendering its assets. On maturity date, there are two possibilities of the firm's asset value, larger or less than the promised payment.

When the asset value is larger than the promised payment on the bond issue, the payment is made based on its equity. On the other hand, when the asset is less than the promised payment then the promised payment will not be able to make although the bank sells all their asset. Therefore the bank chooses to default. In this case, a guarantor can take place to fulfill the promised payment and the bank should surrender the asset to the guarantor. For this occasion, the guarantor charges a cost on the bank to be insured or a premium.

Merton [7] discussed the valuation of deposit insurance as an option pricing problem based on Black-Scholes model. In Figure 1 and Figure 2, the similarities between the deposit insurance and option mechanism are described. Briefly, the stock as the underlying asset of option contract is similar to the bank's asset. The bank and guarantor of deposit insurance are considered as the holder of the deposit insurance and the writer of deposit insurance. In the following section, a mathematical model development of deposit insurance with constant volatility is presented.

\section{A Deposit Insurance Model with a Constant Volatility}

The mathematical model of deposit insurance has been proposed by Merton [7] based on a Black-Scholes model. For more clarity to the reader, the deposit insurance's model development will be derived based on Merton's paper.

The dynamic of bank's asset value $V$ is assumed to follow a geometric Brownian motion,

$$
d V=\mu V d t+\sigma V d W .
$$

where $\mu$ is the expected rate of return, $\sigma$ is the volatility and $W$ is the standard Wiener process.

Supposed that a portfolio consists of one deposit insurance $G$ and and $\Delta=\frac{\partial G}{\partial V}$ unit of bank's assets $V$. Thus, the portfolio is

$$
\Pi=-G+\frac{\partial G}{\partial V} V
$$

If the deposit insurance value $G(V, t)$ depends only on $V$ and $t$, then by using Ito's lemma based on $\mathrm{Eq}(1)$ and $\mathrm{Eq}(2)$, the infinitesimal change of the deposit insurance value is denoted by,

$$
d G=\left(\frac{\partial G}{\partial V} \mu V+\frac{\partial G}{\partial t}+\frac{1}{2} \frac{\partial^{2} G}{\partial V^{2}} \sigma^{2} V^{2}\right) d t+\frac{\partial G}{\partial V} \sigma V d W .
$$

$\mathrm{Eq}(4)$ is called Ito's lemma for the case of deposit insurance discussed here. 


\section{PUT OPTIONS MECHANISM}



Figure 1: Put Option Mechanism

\section{DEPOSIT INSURANCE MECHANISM}

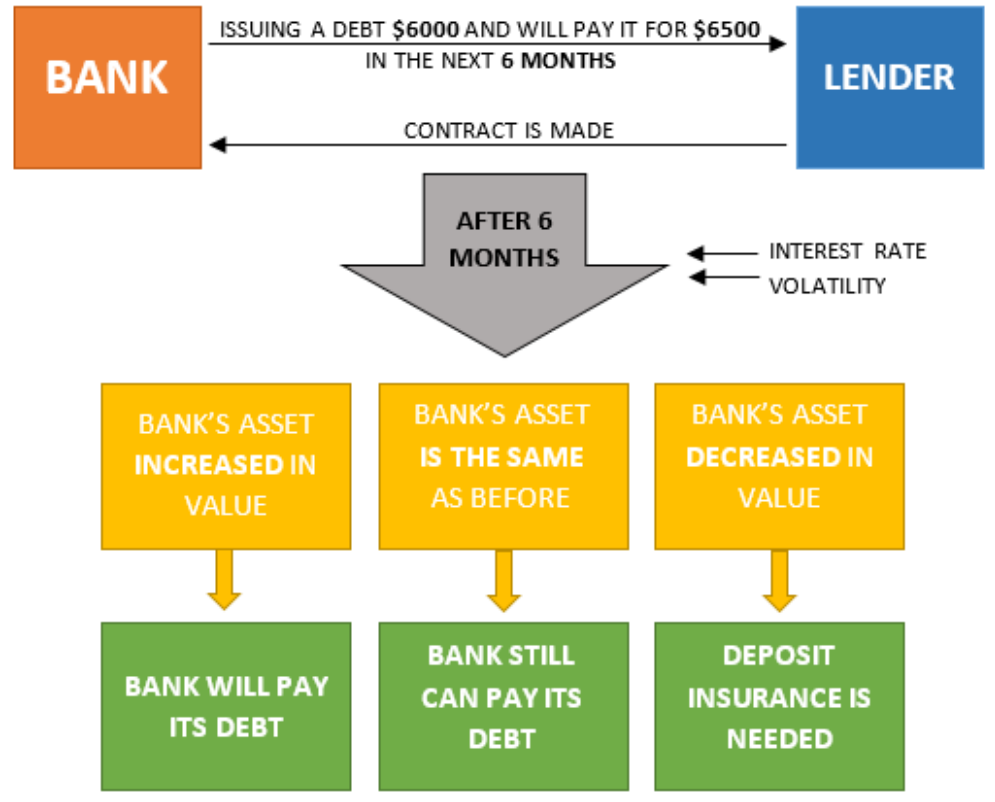

Figure 2: Deposit Insurance Mechanism 
An infinitesimal change of the portfolio value implies that,

$$
\begin{aligned}
d \Pi & =-d G+\frac{\partial G}{\partial V} d V \\
& =-\left(\frac{\partial G}{\partial V} \mu V+\frac{\partial G}{\partial t}+\frac{1}{2} \frac{\partial^{2} G}{\partial V^{2}} \sigma^{2} V^{2}\right) d t+\frac{\partial G}{\partial V} \sigma V d W+\frac{\partial G}{\partial V}(\mu V d t+\sigma V d W) \\
& =-\left(\frac{\partial G}{\partial t}+\frac{1}{2} \frac{\partial^{2} G}{\partial V^{2}} \sigma^{2} V^{2}\right) d t
\end{aligned}
$$

By assuming the portfolio in any bank must be the same with rate of return of a short-termrisk-free bank's assets with interest rate $r$, and substituting $\mathrm{Eq}(4)$, it follows that,

$$
\begin{aligned}
d \Pi_{B} & =r \Pi_{S} d t \\
\left(\frac{\partial G}{\partial t}+\frac{1}{2} \frac{\partial^{2} G}{\partial V^{2}} \sigma^{2} V^{2}\right) d t & =\left(r G-r V \frac{\partial G}{\partial V}\right) d t
\end{aligned}
$$

and $\mathrm{Eq}(5)$ implies,

$$
\frac{\partial G}{\partial t}+\frac{1}{2} \sigma^{2} V^{2} \frac{\partial^{2} G}{\partial V^{2}}+\frac{\partial G}{\partial V} r V-r G=0
$$

$\mathrm{Eq}(6)$ is the so called the Black-Scholes model of the deposit insurance with a constant volatility.

Now the cost of deposit insurance is observed at maturity date $T$ and it is denoted by $G(V, T)$. On maturity date, the value of the debt is $\min [V, B]$. If the bank is able to pay $(V>B)$, then the bondholder will receive $B$ and and the bank will have $V-B$ respectively. If the bank fails to pay $(V<B)$, then the bondholder still receive $B$, however the bank will go bankrupt or default. In abbreviate form, on maturity date $T$, the equity will become $\max [V-B, 0]$ and the value of the debt is always $B$.

Assume, the claim of the guarantor is 0 when the bank is able to pay and $V-B$ when the bank fails to pay. It can be denoted as $\min [V-B, 0]$. If the bank must guarantee the depositor's assets, there must be cash inflows to a bank in amount of $-\min [V-B, 0]$ or can be written as $\max [B-V, 0]$. Then, it can be concluded $G(V, T)=\max [B-V, 0]$ or can be denoted as $(B-V)^{+}$. Afterwards, using the following assumptions, if the bank has no assets, then the deposit insurance would be unnecessary. This case can be written as $G(0, t)=0$. If the bank has a big amount of assets, then the deposit insurance would be also needless. This occurence is denoted by $\lim _{V \rightarrow \infty} G(V, t)=0$.

As a summary the complete model of the deposit insurance can be written as,

$$
\left\{\begin{array}{l}
\frac{\partial G}{\partial t}+\frac{1}{2} \sigma^{2} V^{2} \frac{\partial^{2} G}{\partial V^{2}}+\frac{\partial G}{\partial V} r V-r G=0 \\
G(0, t)=0 \\
G(V, T)=(B-V)^{+} \\
\lim _{V \rightarrow \infty} G(V, t)=0 .
\end{array}\right.
$$

The PDE system in $\operatorname{Eq}(7)$ is then to be solved using a Fourier transform. 


\section{Fourier Transform}

The definition of a Fourier transform is as follows,

$$
\mathcal{F}\{g\}=\int_{-\infty}^{\infty} e^{i \zeta x} g(x) d x=f(\zeta) .
$$

which is a mapping from real domain $\mathbb{R}$ into complex domain $\mathbb{C}$ and is denoted by $\mathcal{F}: \mathbb{R} \rightarrow \mathbb{C}$ for every $\zeta \in \mathbb{R}$ and $i=\sqrt{-1}$. Subsequently, the inverse of Fourier transform in $\operatorname{Eq}(8)$ is determined by,

$$
g(x)=\mathcal{F}^{-1}\{f(\zeta)\}=\frac{1}{2 \pi} \int_{-\infty}^{\infty} e^{-i \zeta x} f(\zeta) d \zeta
$$

Solving the deposit insurance PDE in $\mathrm{Eq}(7)$ using Fourier transform should consider the Fourier properties in the following so that the solution can be obtained in Fourier space,

1. $\mathcal{F}\{b g+c h\}=b \mathcal{F}\{g\}+c \mathcal{F}\{h\}$

2. $\mathcal{F}\left\{g^{\prime}\right\}=-i \zeta f(\zeta)$, if $\lim _{|x| \rightarrow \infty} g(x)=0$

3. $\mathcal{F}\left\{g^{\prime \prime}\right\}=-\zeta^{2} f(\zeta)$, if $\lim _{|x| \rightarrow \infty} g^{\prime}(x)=0$.

In reverting the value obtained in Fourier space, some properties of convolution are required and they are denoted as follows,

$$
\begin{aligned}
\mathcal{F}\{g(x, \tau) * h(x, \tau)\} & =\mathcal{F}\{g(x, \tau)\} \mathcal{F}\{h(x, \tau) .\} \\
\mathcal{F}^{-1}\{g(x, \tau) * h(x, \tau)\} & =\mathcal{F}^{-1}\{g(x, \tau)\} \mathcal{F}^{-1}\{h(x, \tau)\} .
\end{aligned}
$$

\section{Solution Process of Deposit Insurance using Fourier Transform}

The PDE of deposit insurance price in $\mathrm{Eq}(7)$ is solved using a Fourier transform discussed in the previous section. For a simplification, the equation is non-dimensionalized using the following transformation,

$$
x=\ln \left(\frac{V}{B}\right) \Longleftrightarrow V=B e^{x}, \tau=\frac{\sigma^{2}}{2}(T-t), Q(x, \tau)=\frac{e^{-2 x} G(V, t)}{B},
$$

and by letting $\frac{2 r}{\sigma^{2}}=k, \operatorname{Eq}(7)$ can be represented as,

$$
-\frac{\partial Q}{\partial \tau}+k\left(\frac{\partial Q}{\partial x}+2 Q\right)+\left(\frac{\partial^{2} Q}{\partial x^{2}}+3 \frac{\partial Q}{\partial x}+2 Q\right)-k Q=0
$$

Before applying the Fourier transform, the boundary conditions in $\mathrm{Eq}(7)$ should be clarified. First, it is easy to check that,

$$
(B-V)^{+} \leq G(V, t) \leq V .
$$


and using the non-dimensionalization transformation, the inequality can be written as,

$$
\left(B-B e^{x}\right)^{+} \leq B e^{2 x} Q(x, \tau) \leq B e^{x} .
$$

As the value of $B>0$ implies $B e^{2 x}>0$, each side can be divided with $B e^{2 x}$ without changing the sign of inequality. Then it is obtained

$$
\left(e^{-2 x}-e^{-x}\right)^{+} \leq Q(x, \tau) \leq e^{-x}
$$

To clarify whether the properties of Fourier transform are satisfied, it is required to get,

$$
\begin{aligned}
& \lim _{|x| \rightarrow \infty} Q(x, \tau)=0 \\
& \lim _{|x| \rightarrow \infty} Q^{\prime}(x, \tau)=0 .
\end{aligned}
$$

Accordingly, based on the properties,

1. $\lim _{|x| \rightarrow \infty} Q(x, \tau)=0$. In this case, two conditions should be assured, $\lim _{x \rightarrow \infty} Q(x, \tau)=0$ and $\lim _{x \rightarrow-\infty} Q(x, \tau)=0$. From inequality in $\mathrm{Eq}(14)$, if the limit of all sides for $x \rightarrow \infty$, it can be obtained that,

$$
\begin{aligned}
\lim _{x \rightarrow \infty}\left(e^{-2 x}-e^{-x}\right)^{+} & \leq \lim _{x \rightarrow \infty} Q(x, \tau) \leq \lim _{x \rightarrow \infty} e^{-x} \\
0 & \leq \lim _{x \rightarrow \infty} Q(x, \tau) \leq 0 .
\end{aligned}
$$

It follows from Squeeze Theorem in Real Analysis, it is concluded that,

$$
\lim _{x \rightarrow \infty} Q(x, \tau)=0 .
$$

After that, if the limit in all sides for $x \rightarrow-\infty$, it is obtained that,

$$
\begin{aligned}
\lim _{x \rightarrow-\infty}\left(e^{-2 x}-e^{-x}\right)^{+} & \leq \lim _{x \rightarrow-\infty} Q(x, \tau) \leq \lim _{x \rightarrow-\infty} e^{-x} \\
0 & \leq \lim _{x \rightarrow-\infty} Q(x, \tau) \leq \infty .
\end{aligned}
$$

From this inequality, we can choose $\lim _{x \rightarrow-\infty} Q(x, \tau)=0$. Regarding to the $\mathrm{Eq}(16)$ and (17), it can be concluded as follows,

$$
\lim _{|x| \rightarrow \infty} Q(x, \tau)=0
$$

2. $\lim _{|x| \rightarrow \infty} Q^{\prime}(x, \tau)=0$. Since (i) satisfies, we can conclude,

$$
\lim _{|x| \rightarrow \infty} Q^{\prime}(x, \tau)=0
$$

Since the properties of Fourier transform are satisfied, the Fourier transform can be applied to deposit insurance model which is denoted as, 


$$
\left\{\begin{array}{l}
-\frac{\partial Q}{\partial \tau}+k\left(\frac{\partial Q}{\partial x}+2 Q\right)+\left(\frac{\partial^{2} Q}{\partial x^{2}}+3 \frac{\partial Q}{\partial x}+2 Q\right)-k Q=0 \\
\lim _{|x| \rightarrow \infty} Q(x, \tau)=0 \\
Q(x, 0)=\left(e^{-2 x}-e^{-x}\right)^{+} .
\end{array}\right.
$$

The transformation of PDE of deposit insurance into the Fourier space results to an ODE in the following form,

$$
\frac{f_{\tau}}{f}=k(1-i \zeta)+\left(2-3 i \zeta-\zeta^{2}\right)
$$

and the solution of $\mathrm{Eq}(21)$ is

$$
f(\zeta, \tau)=e^{(k+2) \tau} f(\zeta, 0) e^{\left(-i \zeta(k+3)-\zeta^{2}\right) \tau} .
$$

To obtain the solution in the original time space, the Fourier inversion is applied. By recalling that a characteristic function of a random variable $X$ where $X \sim N\left(\mu, \sigma^{2}\right)$ is given by $e^{i \zeta \mu+\frac{1}{2} \sigma^{2} \zeta^{2}}$. The characteristic function is a Fourier transform function of the probability density function of $X$. Taking the part of $\mathrm{Eq}(22)$ as its similarity to the characteristic function of a normal distribution of $X$,

$$
\phi(\zeta)=e^{\left(-i \zeta(k+3)-\zeta^{2}\right) \tau}
$$

the mean and variance are $-(k+3) \tau$ and $2 \tau$ respectively. It is concluded that,

$$
e^{\left(-i \zeta(k+3)-\zeta^{2}\right) \tau}=\mathcal{F}\left\{\frac{1}{\sqrt{2 \pi 2 \tau}} e^{-\frac{((\cdot)+(k+3) \tau)^{2}}{2(2 \tau)}}\right\}=\mathcal{F}\left\{\frac{1}{2 \sqrt{\pi \tau}} e^{-\frac{((\cdot)+(k+3) \tau)^{2}}{4 \tau}}\right\} .
$$

where $(\cdot)$ denotes any variable. Consequently, $\mathrm{Eq}(23)$ is written as

$$
\begin{gathered}
f(\zeta, \tau)=e^{(k+2) \tau} f(\zeta, 0) e^{\left(-i \zeta(k+3)-\zeta^{2}\right) \tau} \\
\mathcal{F}\{Q(\cdot, \tau)\}=e^{(k+2) \tau} \mathcal{F}\{Q(\cdot, 0)\} \mathcal{F}\left\{\frac{1}{2 \sqrt{\pi \tau}} e^{-\frac{((\cdot)+(k+3) \tau)^{2}}{4 \tau}}\right\} .
\end{gathered}
$$

By convolution properties on Fourier transform, we will have,

$$
\begin{gathered}
\mathcal{F}\{Q(\cdot, \tau)\}=e^{(k+2) \tau} \mathcal{F}\left\{Q(\cdot, 0) * \frac{1}{2 \sqrt{\pi \tau}} e^{-\frac{((\cdot)+(k+3) \tau)^{2}}{4 \tau}}\right\} \\
\mathcal{F}^{-1}\{\mathcal{F}\{Q(\cdot, \tau)\}\}=e^{(k+2) \tau} \mathcal{F}^{-1}\left\{\mathcal{F}\left\{Q(\cdot, 0) * \frac{1}{2 \sqrt{\pi \tau}} e^{-\frac{((\cdot)+(k+3) \tau)^{2}}{4 \tau}}\right\}\right\} \\
Q(\cdot, \tau)=e^{(k+2) \tau}\left(Q(\cdot, 0) * \frac{1}{2 \sqrt{\pi \tau}} e^{-\frac{((\cdot)+(k+3) \tau)^{2}}{4 \tau}}\right) .
\end{gathered}
$$

Let $W(\omega, \tau)=\frac{1}{2 \sqrt{\pi \tau}} e^{-\frac{(\omega+(k+3) \tau)^{2}}{4 \tau}}$, it implies $Q(\omega, \tau)=e^{(k+2) \tau}(Q(\omega, 0) * W(\omega, \tau))$. Then,

$$
\begin{aligned}
& Q(\omega, \tau)=e^{(k+2) \tau}(Q(\omega, 0) * W(\omega, \tau)) \\
& Q(\omega, \tau)=\frac{e^{(k+2) \tau}}{2 \sqrt{\pi \tau}} \int_{-\infty}^{\infty} Q(\omega, 0) e^{-\frac{(\omega-x-(k+3) \tau)^{2}}{4 \tau}} d \omega .
\end{aligned}
$$


Substitute the initial condition $Q(\omega, 0)=\left(e^{-2 \omega}-e^{-\omega}\right)^{+}$to $\operatorname{Eq}(26)$ and we will have,

$$
Q(\omega, \tau)=\frac{e^{(k+2) \tau}}{2 \sqrt{\pi \tau}} \int_{-\infty}^{\infty}\left(e^{-2 \omega}-e^{-\omega}\right)^{+} e^{-\frac{(\omega-x-(k+3) \tau)^{2}}{4 \tau}} d \omega
$$

Note that, $e^{-2 \omega}-e^{-\omega}$ will have negative value if and only if $\omega>0$, it implies,

$$
Q(\omega, \tau)=\frac{e^{(k+2) \tau}}{2 \sqrt{\pi \tau}} \int_{-\infty}^{0} e^{-\frac{8 \omega \tau+(\omega-x-(k+3) \tau)^{2}}{4 \tau}} d \omega-\frac{e^{(k+2) \tau}}{2 \sqrt{\pi \tau}} \int_{-\infty}^{0} e^{\omega} e^{-\frac{8 \omega \tau+(\omega-x-(k+3) \tau)^{2}}{4 \tau}} d \omega .
$$

To make the calculation easier, let

$$
\begin{gathered}
A_{1}=\frac{e^{(k+2) \tau}}{2 \sqrt{\pi \tau}} \int_{-\infty}^{0} \exp \left\{-\frac{8 \omega \tau+(\omega-x-(k+3) \tau)^{2}}{4 \tau}\right\} d \omega . \\
A_{2}=\frac{e^{(k+2) \tau}}{2 \sqrt{\pi \tau}} \int_{-\infty}^{0} \exp \{\omega\} \exp \left\{-\frac{8 \omega \tau+(\omega-x-(k+3) \tau)^{2}}{4 \tau}\right\} d \omega .
\end{gathered}
$$

The solutions of $A_{1}$ and $A_{2}$ in $\operatorname{Eq}(28)$ and (29) will be in the form of a cumulative density function of a standard normal distribution. By using a function $u=\frac{\omega}{\sqrt{2 \tau}} \Rightarrow \sqrt{2 \tau} d u=d \omega$ in $A_{1}$ and $A_{2}$ in $\operatorname{Eq}(28)$ and (29), this implies $\omega=-\infty \Rightarrow u=-\infty$ and $\omega=0 \Rightarrow u=0$. Then, the solutions are,

$$
\begin{array}{r}
A_{1}=e^{-k \tau-2 x} \Phi\left(\frac{-x-(k-1) \tau}{\sqrt{2 \tau}}\right) . \\
A_{2}=e^{-x} \Phi\left(\frac{-x-(k+1) \tau}{\sqrt{2 \tau}}\right) .
\end{array}
$$

Shortly, the result of $\mathrm{Eq}(26)$ after the inversion is

$$
Q(x, \tau)=e^{-k \tau-2 x} \Phi\left(\frac{-x-(k-1) \tau}{\sqrt{2 \tau}}\right)-e^{-x} \Phi\left(\frac{-x-(k+1) \tau}{\sqrt{2 \tau}}\right) .
$$

In order to fully reverting the solution back to its original space, then non-dimensionalized system is reverting to dimensionalized one, and the result is

$$
\begin{aligned}
G(V, t) & =B e^{-r(T-t)} \Phi\left(z_{2}\right)-V \Phi\left(z_{1}\right) \\
z_{1} & =\frac{\ln (B / V)-\left(r+\frac{\sigma^{2}}{2}\right)(T-t)}{\sigma \sqrt{(T-t)}} \\
z_{2} & =z_{1}+\sigma \sqrt{T-t} .
\end{aligned}
$$

Eq (33) is then called the analytical solution of a deposit insurance pricing based on the BlackScholes model with a constant volatility. This solution is similar to Merton's paper about analytical solution of deposit insurance which are presented without further explanation about the solution process [7]. By using the Fourier transform to obtain the analytical solution similar to Merton, it is easier to extend the case into more complicated ones. This is the interest of applying Fourier transform for solving the mathematical model of deposit insurance. 


\section{Numerical Results and Discussion}

In this section, some numerical results of deposit insurance for some parameters value are presented. First, a simulation result using the same parameters value in Merton's paper [7] is conducted and the result is shown in Figure 3. A deposit-to-asset ratio is introduced as a common ratio used in financial practice as an indicator of a financial stability of the bank.

If the deposit-to-asset value ratio is less than 0.5 for $\sigma=25 \%$ and a 1 year depsoit insurance, the asset as the collateral of the deposit is large enough so that the risk of the deposit insurance is low. This implies the premium of the deposit insurance is very low. In contrast, if the depositto-asset value ratio is more than 0.5 , the deposit insurance's premium increases as the risk of the insurer or guarantor becomes higher. The deposit-to-asset value ratio is directly used without considering the interest rate value, so the premium of deposit insurance in this case is independent of the risk free interest rate.

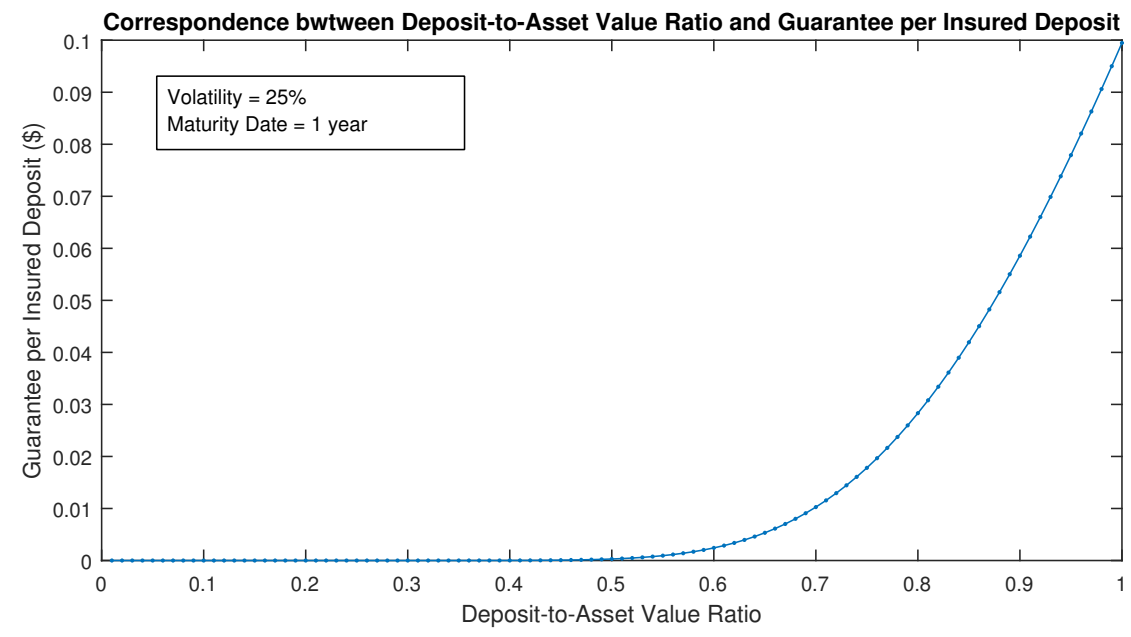

Figure 3: Deposit-to-Asset Value Ration vs Guarantee Cost

In Figure 4, increasing volatility as the variance rate of asset changes leads to a higher premium of deposit insurance. As the changes of asset value happens with a higher rate then the risk of the guarantor will be higher. Consequently, a higher premium of the guarantee is applied to cover the higher risk. Subsequently, recalling the value of deposit-to-asset ratio which is calculated as $R=D / V=B e^{-r T} / V$, by knowing that $V$ is the asset value and $D=B e^{-r T}$ is the present value of bond owned by the bank, the effect of different interest rate and the asset return volatility as the variance of the asset changes rate are investigated.

Although the interest rate is basically affecting the deposit-to-asset ratio, a more briefly presentation of the deposit insurance premium affected by the interest rate is presented. Both, the effect of the interest rate and volatility to the deposit insurance premium can be seen in Table 1, referring to some parameters used in Merton [7] and the value of bond equal to $\operatorname{asset}(B=V)$. As the interest rate increases, the present value of the deposit and the depositto-asset value ratio decreases and subsequently the guarantee cost also decreases for the same variance rate of the asset changes. However, for the same interest rate value and decreasing variance rate of asset changes, the guarantee cost decreases as the risk indicated by the variance rate is lower. 




Figure 4: The Value of Deposit Insurance with Respect to Volatility

Table 1: Value of Bond Equal to Asset - $(B=V=\$ 100)$

\begin{tabular}{|c|c|c|c|c|}
\hline \multirow{2}{*}{$\boldsymbol{\sigma}^{\mathbf{2}}$} & $\begin{array}{c}\text { Interest } \\
\text { Rate }\end{array}$ & Deposit(D) & $\begin{array}{c}\text { Deposit-to- } \\
\text { Asset Value } \\
\text { Ratio (R) }\end{array}$ & $\begin{array}{c}\text { Guarantee } \\
\text { per Insured } \\
\text { Deposit (\$) }\end{array}$ \\
\hline \multirow{3}{*}{0.006} & $5 \%$ & 95.123 & 0.95 & 0.0124270976 \\
\cline { 2 - 5 } & $10 \%$ & 90.484 & 0.90 & 0.0037769929 \\
\cline { 2 - 5 } 0 & $15 \%$ & 86.071 & 0.86 & 0.0008385369 \\
\hline \multirow{3}{*}{0055} & $5 \%$ & 95.123 & 0.95 & 0.0113427478 \\
\cline { 2 - 5 } & $10 \%$ & 90.484 & 0.90 & 0.0031980706 \\
\hline \multirow{3}{*}{0.005} & $15 \%$ & 86.071 & 0.86 & 0.0006383699 \\
\cline { 2 - 5 } & $5 \%$ & 95.123 & 0.95 & 0.0102311325 \\
\cline { 2 - 5 } & $10 \%$ & 90.484 & 0.90 & 0.0026403854 \\
\hline \multirow{3}{*}{0.0045} & $15 \%$ & 86.071 & 0.86 & 0.0004644905 \\
\cline { 2 - 5 } & $5 \%$ & 95.123 & 0.95 & 0.0090913535 \\
\cline { 2 - 5 } & $10 \%$ & 90.484 & 0.90 & 0.0021100544 \\
\cline { 2 - 5 } & $15 \%$ & 86.071 & 0.86 & 0.0003185836 \\
\cline { 2 - 5 } & $5 \%$ & 95.123 & 0.95 & 0.0079231004 \\
\hline
\end{tabular}

For the value of bond less than the asset value $B<V$, the simulation results for some different values of interest rate and volatility (variance rate of asset changes) are presented in Table 2 and shows similar behavior with the values for equal value of bond and asset value in Table 1. Lower deposit-to-asset value ratio as a consequence of the bond value less than the asset, the guarantee cost decreases and reaches almost worthless for smaller variance rate $\left(\sigma^{2}=0.004\right)$. Smaller variance rate means that the lower risk is exposed to the deposit insurance and the asset is large enough as the collateral of the deposit, hence the premium cost is very cheap. 
Table 2: Value of Bond Less than Asset $(\$ 100)-(B<V=\$ 80<\$ 100)$

\begin{tabular}{|c|c|c|c|c|}
\hline \multirow{2}{*}{$\boldsymbol{\sigma}^{\mathbf{2}}$} & $\begin{array}{c}\text { Interest } \\
\text { Rate }\end{array}$ & Deposit & $\begin{array}{c}\text { Deposit-to- } \\
\text { Asset Value } \\
\text { Ratio }\end{array}$ & $\begin{array}{c}\text { Guarantee } \\
\text { per Insured } \\
\text { Deposit (\$) }\end{array}$ \\
\hline \multirow{3}{*}{0.006} & $5 \%$ & 76.098 & 0.76 & 0.0000046730 \\
\cline { 2 - 5 } & $10 \%$ & 72.387 & 0.72 & 0.0000002995 \\
\cline { 2 - 5 } 0 & $15 \%$ & 68.857 & 0.69 & 0.0000000131 \\
\hline \multirow{3}{*}{0055} & $5 \%$ & 76.098 & 0.76 & 0.0000023627 \\
\cline { 2 - 5 } & $10 \%$ & 72.387 & 0.72 & 0.0000001205 \\
\hline \multirow{3}{*}{0.005} & $15 \%$ & 68.857 & 0.69 & 0.0000000040 \\
\cline { 2 - 5 } & $5 \%$ & 76.098 & 0.76 & 0.0000010541 \\
\cline { 2 - 5 } 0.0045 & $10 \%$ & 72.387 & 0.72 & 0.0000000409 \\
\cline { 2 - 5 } & $15 \%$ & 68.857 & 0.69 & 0.0000000010 \\
\hline \multirow{3}{*}{0.004} & $10 \%$ & 76.098 & 0.76 & 0.0000003986 \\
\cline { 2 - 5 } & $15 \%$ & 68.387 & 0.72 & 0.0000000111 \\
\cline { 2 - 5 } & $5 \%$ & 76.098 & 0.69 & 0.0000000002 \\
\hline
\end{tabular}

Bigger bond value than the asset value leads to higher risk exposed to the guarantor. Therefore, the premium of deposit insurance charged to the insured bank is higher. Simulation results with different value of interest rate and the variance rate of asset changes are presented in Table 3 .

Table 3: Value of Bond more than Asset $(\$ 100)-(B>V=\$ 100>\$ 80)$

\begin{tabular}{|c|c|c|c|c|}
\hline \multirow{2}{*}{$\boldsymbol{\sigma}^{\mathbf{2}}$} & $\begin{array}{c}\text { Interest } \\
\text { Rate }\end{array}$ & Deposit & $\begin{array}{c}\text { Deposit-to- } \\
\text { Asset Value } \\
\text { Ratio }\end{array}$ & $\begin{array}{c}\text { Guarantee } \\
\text { per Insured } \\
\text { Deposit (\$) }\end{array}$ \\
\hline \multirow{3}{*}{0.006} & $5 \%$ & 95.123 & 1.19 & 0.1592967755 \\
\cline { 2 - 5 } & $10 \%$ & 90.484 & 1.13 & 0.1175963482 \\
\cline { 2 - 5 } 0 & $15 \%$ & 86.071 & 1.08 & 0.0774399674 \\
\hline \multirow{3}{*}{0055} & $5 \%$ & 95.123 & 1.19 & 0.1592078694 \\
\cline { 2 - 5 } & $10 \%$ & 90.484 & 1.13 & 0.1172659135 \\
\hline \multirow{3}{*}{0.005} & $15 \%$ & 86.071 & 1.08 & 0.0766443180 \\
\cline { 2 - 5 } & $5 \%$ & 95.123 & 1.19 & 0.1591352617 \\
\cline { 2 - 5 } & $10 \%$ & 90.484 & 1.13 & 0.1169609264 \\
\hline \multirow{3}{*}{0.0045} & $15 \%$ & 86.071 & 1.08 & 0.0758477284 \\
\cline { 2 - 5 } & $5 \%$ & 95.123 & 1.19 & 0.1590787140 \\
\hline & $10 \%$ & 90.484 & 1.13 & 0.1166855255 \\
\cline { 2 - 5 } & $15 \%$ & 86.071 & 1.08 & 0.0750540181 \\
\cline { 2 - 5 } & $5 \%$ & 95.123 & 1.19 & 0.1590374317 \\
\hline
\end{tabular}




\section{Conclusion}

The valuation of deposit insurance is obtained using a Fourier transform analytically. The partial differential equation of deposit insurance is transformed into the ordinary differential equation using the Fourier transform and solved in Fourier space. An analytical inversion can be applied to revert the solution back to its original space. The interest in solving the deposit insurance governing equation using the Fourier transform is that an ease to extend the case into a more complicated ones and solving it using the same transform method.

Furthermore, the behavior of the value of deposit insurance with respect to some parameters value are investigated. The deposit-to-asset value ration is clearly affecting the premium of the deposit insurance. As the interest rate decreases and consequently the value of deposit-to-asset value ratio also decreases, the premium also decreases. Higher deposit-to-asset value ration leads to a higher premium of deposit insurance as the risk faced by the insurer is higher.

\section{Acknowledgments}

The authors would like to thank READI Project Grant for Applied Research 2017 and Department of Mathematics, Sepuluh Nopember Institute of Technology for funding.

\section{References}

[1] Cerrone, R. Deposit guarantee reform in Europe: does European deposit insurance scheme increase banking stability? Journal of Economic Policy Reform. 2018. 21(3): 224-239.

[2] Duan, J.-C. and Yu, M.-T. Assessing the cost of Taiwan's deposit insurance. Pacific-Basin Finance Journal. 1994. 2(1): 73-90.

[3] Bank-Indonesia. Deposit insurance company. http://www.bi.go.id/en/tentangbi/manajemen-krisis/lembaga-penjamin-simpanan/Contents/Default.aspx. 2017.

[4] Zhang, Y. and Shi, B. Systematic risk and deposit insurance pricing: Based on market model and option pricing theory. China Finance Review International. 2017. 7(4): 390406.

[5] Le Courtois, O. and Su, X. Structural pricing of CoCos and deposit insurance with regime switching and jumps. 2018.

[6] Liu, H., Li, R. and Yuan, J. Deposit insurance pricing under GARCH. Finance Research Letters. 2018.

[7] Merton, R. C. An analytic derivation of the cost of deposit insurance and loan guarantees an application of modern option pricing theory. Journal of Banking \& Finance. 1977. 1(1): 3 - 11. ISSN 0378-4266.

[8] Marcus, A. J. and Shaked, I. The valuation of FDIC deposit insurance using option-pricing estimates. Journal of Money, Credit and Banking. 1984. 16(4): 446-460.

[9] Black, F. and Scholes, M. The Pricing of Options and Corporate Liabilities. Journal of Political Economy. 1973. 81(3): 637-654.

[10] Carr, P. and Madan, D. Option valuation using the fast Fourier transform. Journal of computational finance. 1999. 2(4): 61-73. 
[11] Fang, F. and Oosterlee, C. W. A novel pricing method for European options based on Fourier-cosine series expansions. SIAM Journal on Scientific Computing. 2008. 31(2): 826-848.

[12] Jiang, L. Mathematical Modelling and Methods of Option Pricing. first edition Edition. Singapore:World Scientific. 2005.

[13] Wilmott, P., Howison, S. and Dewynne, J. The Mathematics of Financial Derivatives: A Student Introduction. first edition Edition. Cambridge University Press,. 1995. 